\title{
PRESENCE OF CIRRHOSIS IN NEWLY DIAGNOSED HEPATITIS C PATIENTS WITHOUT PRIOR HISTORY OF CHRONIC LIVER DISEASE.
}

\author{
1. MBBS, FCPS (Medicine), \\ FCPS (Gestroentrology) \\ Professor \\ Department of Medicine \\ Sheikh Zayed Medical College/ \\ Hospital, Rahim Yar Khan. \\ 2. MBBS, FCPS (Medicine) \\ Assistant Professor \\ Department of Medicine \\ Sheikh Zayed Medical College/ \\ Hospital, Rahim Yar Khan. \\ 3. MBBS, FCPS (Medicine) \\ Assistant Professo \\ Department of Medicine \\ Sheikh Zayed Medical College/ \\ Hospital, Rahim Yar Khan. \\ Correspondence Address: \\ Dr. Irfan Ahmad \\ C4, Medical Colony, \\ Sheikh Zaid Medical College, Rahim \\ Yar Khan. \\ uhirfan@yahoo.com \\ 03334365708
}

Article received on:

21/01/2019

Accepted for publication:

27/05/2019

\section{INTRODUCTION}

Cirrhosis is an important cause of morbidity and mortality worldwide ${ }^{1}$ and it is amongst the commonest diseases in our medical wards. Once it is advanced, it is irreversible; nothing can be done apart from monitoring for or treating its various complications as liver transplantation is not readily available in our setup. The risk of developing complications like ascites, jaundice, variceal bleeding and encephalopathy (hepatic decompensation) is $3.9 \%$ per year $^{2}$ which have considerable mortality rates. Once cirrhosis has developed, the risk of developing hepatocellular carcinoma is 0 to 3 percent per year in various reports. ${ }^{2,3}$ In our region hepatitis $\mathrm{B}$ and $\mathrm{C}$ are very common, especially hepatitis C. ${ }^{4,5}$ Most patients of acute hepatitis $\mathrm{C}$ and perinatally acquired hepatitis B developed chronic hepatitis. ${ }^{6}$ So cirrhosis here is mostly caused by chronic hepatitis $C$ and to some extent hepatitis $\mathrm{B}$, other causes are rare. ${ }^{7-}$
10 Many patients of chronic hepatitis may be asymptomatic. ${ }^{11}$ Others may have non-specific symptoms like fatigue, myalgia, arthralgia and weakness, ${ }^{12}$ and some may have mild cognitive impairment. ${ }^{13}$ Due to this reason many chronic hepatitis B and C patients have advanced liver disease when diagnosed.

Awareness about hepatitis $B$ and $C$ in our population has increased over recent years. Many people get or advised by general practitioners to get themselves tested for these viruses either routinely or on presence of nonspecific symptoms. But it is thought that most of the patients still remain undiagnosed till they develop cirrhosis. The purpose of our study was to identify regional data regarding presence of advanced liver disease in chronic hepatitis C patients at presentation to health facility. This would help us to decide whether community 
based screening program be instituted for early detection of hepatitis viruses. The objective of this study was to determine frequency of cirrhosis in those newly diagnosed hepatitis $C$ patients who had no previous history of chronic liver disease.

\section{PATIENTS AND METHODS}

This descriptive study was carried out in Hepatitis Clinic, Sheikh Zayed Medical College/Hospital, Rahim Yar Khan. All patients who attended Hepatitis Clinic for chronic hepatitis $C$ treatment from March to September 2018 were considered for inclusion in the study. All patients who were recently (within three months) diagnosed as a case of hepatitis $\mathrm{C}$ were included in the study. The patients who have already been diagnosed as a case of hepatitis $C$ for more than three months and whose serology status was not known previously but they were known to have liver disease were excluded from the study. The following features of the patients who fulfilled inclusion/exclusion criteria were noted: age and gender, symptoms, and any co-morbidities (diabetes mellitus, hypertension, alcoholism, autoimmune hepatitis, chronic kidney disease, and chronic cardiopulmonary diseases). Among investigations, complete blood count, liver function tests (total bilirubin, ALT, AST), albumin, creatinine, prothrombin time (PT) and ultrasound abdomen findings (hepatomegaly, shrunken liver, splenomegaly, and ascites) were recorded. APRI ${ }^{14}$ and FIB $4{ }^{15}$ scores were also calculated.

Cirrhosis was diagnosed on the basis of:

- Clinical stigmata - clubbing, leukonychia, palmar erythema, spider nevi, peripheral edema, splenomegaly

- Lab investigations - prolonged PT, low albumin

- Ultrasound findings - shrunken liver, splenomegaly, ascites

- $A P R I$ and FIB 4 scores - APRI score 1 or more is $76 \%$ sensitive and $72 \%$ specific for cirrhosis; ${ }^{14}$ FIB 4 score > 3.25 has $97 \%$ specificity for advanced fibrosis. ${ }^{15}$

The data was entered and analyzed using SPSS version 25. The qualitative data was expressed as frequency and percentage. The quantitative data was expressed as mean, standard deviation and range. A $p$ value of $<0.05$ was considered to be significant. Study protocol was approved from Institutional Review Board and Ethical Committee.

\section{RESULTS}

Among 2800 patients who attended the Hepatitis Clinic for the treatment of chronic hepatitis $\mathrm{C}$ during study period, 373 patients were diagnosed to have hepatitis $\mathrm{C}$ infection within 3 months of presentation, and met inclusion/exclusion criteria. One hundred and sixty six patients (44.5\%) were male and 207 (55.5\%) were female. Mean age of patients was $38.51 \pm 12$ years with range from 8 to 82 years. Ninety patients $(24.1 \%)$ were asymptomatic. Common symptoms were malaise and body aches (71.6\% patients). Associated comorbidities were hypertension in 46 (12.3\%) patients, diabetes mellitus in 31 (8.3\%) and renal failure in one $(0.3 \%)$. Two $(0.5 \%)$ patients were alcoholic.

Among these 373 patients included in study, 64 $(17.2 \%)$ had cirrhosis diagnosed on the basis of one of the criteria given above; 52 had Child $A$ and 12 had Child B cirrhosis. Comparison of demographic features and symptoms presence between non-cirrhotic and cirrhotic patients is shown in Table-I. The cirrhotic patients were significantly $(p=0.000)$ older than non-cirrhotic, but gender distribution between these two groups were not significant $(p=0.675)$.

\begin{tabular}{|c|c|c|}
\hline Feature & $\begin{array}{l}\text { Non-cirrhotic } \\
\text { (309 Patients) }\end{array}$ & $\begin{array}{c}\text { Cirrhotic } \\
\text { (64 Patients) }\end{array}$ \\
\hline $\begin{array}{c}\text { Age (years) mean } \\
\pm S D\end{array}$ & $36.74 \pm 11.60$ & $47.09 \pm 10.15$ \\
\hline $\begin{array}{l}\text { Gender } \\
\text { Male } \\
\text { Female }\end{array}$ & $\begin{array}{l}136 \\
173\end{array}$ & $\begin{array}{l}30 \\
34\end{array}$ \\
\hline $\begin{array}{l}\text { Presence of } \\
\text { symptoms } \\
\text { Symptomatic } \\
\text { Asymptomatic }\end{array}$ & $\begin{array}{c}230 \\
79\end{array}$ & $\begin{array}{l}53 \\
11\end{array}$ \\
\hline
\end{tabular}

Fifty nine (92.19\%) cirrhotic patients had splenomegaly. All of these had APRI score 1 or 
more, 46 had FIB-4 score more than 3.25, 18 had prolonged PT, 9 had decreased albumin and 5 had ascites. Three patients met both APRI and FIB-4 criteria having no other features. One along with APRI and FIB-4 criteria had prolonged PT. One patient had ascites and low albumin. Table-II shows serum albumin, PT, APRI and FIB-4 scores in both non-cirrhotic and cirrhotic patients.

\begin{tabular}{|c|c|c|}
\hline Features & $\begin{array}{c}\text { Non- } \\
\text { cirrhotic }\end{array}$ & Cirrhotic \\
\hline $\begin{array}{l}\text { Serum albumin }(\mathrm{g} / \mathrm{dl}) \\
>3.5 \\
2.8-3.5 \\
<2.8\end{array}$ & $\begin{array}{c}305 \\
4 \\
0\end{array}$ & $\begin{array}{c}54 \\
9 \\
1\end{array}$ \\
\hline $\begin{array}{l}\text { PT prolongation (in seconds) } \\
<4 \\
4-6 \\
>6\end{array}$ & $\begin{array}{c}302 \\
7 \\
0\end{array}$ & $\begin{array}{c}45 \\
15 \\
4\end{array}$ \\
\hline $\begin{array}{l}\text { APRI } \\
<0.7 \\
0.7-<1 \\
1-<1.5 \\
1.5-<2 \\
2 \text { or more }\end{array}$ & $\begin{array}{c}223 \\
86 \\
0 \\
0 \\
0\end{array}$ & $\begin{array}{c}1 \\
0 \\
14 \\
10 \\
39\end{array}$ \\
\hline $\begin{array}{l}\text { FIB-4 } \\
<1.45 \\
1.45-3.25 \\
>3.25\end{array}$ & $\begin{array}{c}244 \\
65 \\
0\end{array}$ & $\begin{array}{c}0 \\
14 \\
50\end{array}$ \\
\hline
\end{tabular}

\section{DISCUSSION}

Hepatitis C infection is common in our region. ${ }^{4,5}$ Most patients who acquire hepatitis $C$ develop chronic hepatitis. ${ }^{6}$ Worldwide, 71 million people are suffering from chronic hepatitis $\mathrm{C}^{16}$, many of these patients are not aware of their disease. In comparison with uninfected persons, patients with chronic hepatitis $\mathrm{C}$ die early due to cirrhosis and hepatocellular carcinoma. ${ }^{17}$ Chronic hepatitis $\mathrm{C}$ is a major cause of cirrhosis, especially in our country. ${ }^{7-10,18}$ Treatment of chronic hepatitis C resulting in sustained virological response (SVR) may cause regression of hepatic fibrosis and reduction of risk of complications of cirrhosis ${ }^{19}$ but patients with advanced disease remain at risk of life threatening sequelae. The exact time when liver fibrosis becomes irreversible cannot be predicted.
Patients with chronic hepatitis C are usually asymptomatic or may have non-specific symptoms. Muhammad Umar et al showed that $25 \%$ patients of chronic hepatitis C were asymptomatic and others had vague symptoms like malaise, myalgia and fatigue. ${ }^{11}$ Another report revealed that $60 \%$ of these patients had fatigue, myalgia, arthralgia and sleep disturbances. ${ }^{12}$ During compensated phase of cirrhosis, patients may also be asymptomatic or have non-specific symptoms. Our study showed similar results. Due to this reason, many patients of chronic hepatitis $C$ if not screened or incidentally found on testing for another reason remain undiagnosed until they developed features of decompensated cirrhosis. Bell BP et al found that about $20 \%$ patients had cirrhosis when first detected to be suffering from chronic hepatitis. ${ }^{1}$ In our study, $17 \%$ patients had cirrhosis at presentation. It should be kept in mind that we included only those patients who attended Hepatitis Clinic. Many of patients who presented in medical emergency with complications of decompensated cirrhosis like variceal bleeding, hepatic encephalopathy or spontaneous bacterial peritonitis have no previous history of chronic liver disease. Such patients are also seen in medical outpatient. This means that actual percentage of these patients is higher than that we found.

Our cirrhotic patients were slightly younger (mean age 47 years) than those found in two national studies (5320 and $54^{11}$ years). Probably it is due to difference in study design, these two studies included patients with established cirrhosis. Similary, in other studies $58 \%^{7}, 60 \%^{8}$ and $65 \%{ }^{9}$ cirrhotics were male while in our study female were slightly more than male patients, probably because overall female patients were more in our study.

\section{CONCLUSION}

About $17 \%$ chronic hepatitis C patients had cirrhosis at the time of diagnosis. It emphasizes the need of population screening for hepatitis $C$ so that it can be detected at an early stage of chronic liver disease before the development of advanced irreversible stage.

Copyright@ 27 May, 2019. 


\section{REFERENCES}

1. Bell BP, Manos MM, Zaman A, Terrault N, Thomas A, Navarro V, et al. The epidemiology of newly diagnosed chronic liver disease in gastroenterology practices in the United States: Results from population-based surveillance. American Journal of Gastroenterology 2008; 103 (11):2727-36.

2. Fattovich G, Giustina G, Degos F, Tremolada F, Diodati G, Almasio P, et al. Morbidity and mortality in compensated cirrhosis type $C$ : A retrospective follow-up study of 384 patients. Gastroenterology 1997; $112(2): 463-72$.

3. Hu KQ, Tong MJ. The long-term outcomes of patients with compensated hepatitis $\mathbf{C}$ virus-related cirrhosis and history of parenteral exposure in the United States. Hepatology 1999; 29 (4):1311-6.

4. Aslam MN, Nadeem M, Qureshi UF. HEPATITIS B AND C. The Professional Medical Journal. 2016 Jan 10;23(01):25-8.

5. Zafar Majeed, MA Manzoor, Aasma Manzur. Prevalence of hepatitis $B$ and hepatitis $C$ viral infection in the rural population of Rahim Yar Khan. JSZMC 2012; 3 (2):310-3.

6. Grebely J, Page K, Sacks-Davis R, van der Loeff MS, Rice TM, Bruneau J, et al. The effect of female sex, viral genotype, and IL28B genotype on spontaneous clearance of acute hepatitis $\mathbf{C}$ virus infection. Hepatology 2014; 59 (1):109-20.

7. Atif Qureshi, Jamshaid, Siddiqui M, Zafar SA. Clinical spectrum of cirrhosis of liver due to HCV in Jinnah Hospital Lahore. Pak Postgrad Med J 2001; 12 (3):1047.

8. Saleem lqbal, Ruknuddin. Liver cirrhosis in North West Frontier province of Pakistan. JCPSP 2002: 12 (5): 289-91.

9. Muhammad Shahid Aziz, Furrukh Saeed, Muhammad Farooq. Clinical spectrum of cirrhosis liver - a study of 167 cases. Pak Armed Forces Med J 2009; 59 (4):263-4.

10. Purdil Khan, Aziz Ahmad, Noor Muhammad, Taj Muhammad Khan, Bilal Ahmad. Screening of 110 cirrhotic patients for hepatitis B and C at Saidu Teaching Hosptial, Saidu Sharif, Swat. J Ayub Med Coll Abottabad 2009; 21 (1):119-21.
11. Muhammad Umar, Hamama Tul Bushra, Atifa Shoaib, Asim Anwar, Nisar Husain Shah. Spectrum of chronic liver disease due to hepatitis $\mathbf{C}$ virus infection. JCPSP 2000; 10 (10):380-3.

12. Evon DM, Stewart PW, Amador J, Serper M, Lok AS, Sterling RK, et al. A comprehensive assessment of patient reported symptom burden, medical comorbidities, and functional wellbeing in patients initiating direct acting antiviral therapy for chronic hepatitis C: results from a large US multi-center observational study. PLoS One 2018; 13 (8):e0196908.

13. Hilsabeck RC, Perry W, Hassanein TI. Neuropsychological impairment in patients with chronic hepatitis C. Hepatology 2002; 35 (2): 440-6.

14. Lin ZH, Xin YN, Dong QJ, Wang Q, Jiang XJ, Zhan SH, et al. Performance of the aspartate aminotransferaseto-platelet ratio index for the staging of hepatitis C-related fibrosis: an updated meta-analysis. Hepatology. 2011; 53 (3):726-36.

15. Sterling RK, Lissen E, Clumeck N, Sola R, Correa MC, Montaner J, et al. Development of a simple noninvasive index to predict significant fibrosis patients with HIV/ HCV co-infection. Hepatology 2006; 43 (6):1317-25.

16. Polaris Observatory HCV Collaborators. Global prevalence and genotype distribution of hepatitis C virus infection in 2015: A modelling study. Lancet Gastroenterol Hepatol 2017; 2 (3):161-176.

17. Pinchoff J, Drobnik A, Bornschlegel K, Braunstein S, Chan C, Varma JK, et al. Deaths among people with hepatitis $\mathbf{C}$ in New York City, 2000-2011. Clin Infect Dis. 2014; 58 (8): 1047-1054.

18. Niaz Ali Shaikh, Akhtar Ali Baloch, Muhammad Irfan, Aneel Sham Vaswani, Fayaz Ahmad Mughal, Syed Ehsan Ali. Clinical signs of chronic liver disease: Is there any difference in patients with hepatitis $B$ and C. Med Channel 2010; 16(2): 233-6.

19. Nahon P, Bourcier V, Layese R, Audureau E, Cagnot C, Marcellin P, et al. Eradication of hepatitis $\mathbf{C}$ virus infection in patients with cirrhosis reduces risk of liver and non-liver complications. Gastroenterology 2017; 152 (1):142-156, e2.

20. Mansoor Nadeem, M Ali Yousaf, Manzar Zakaria, Tasawar Hussain, Nadir Ali. The value of clinical signs in diagnosis of cirrhosis. Pak J Med Sci 2005; 21 (2): 121-4. 


\title{
Wisdom is learning what to overlook.
}

\author{
"William James"
}

\section{AUTHORSHIP AND CONTRIBUTION DECLARATION}

\begin{tabular}{|c|l|l|}
\hline Sr. \# & Author(s) Full Name & \multicolumn{1}{|c|}{ Contribution to the paper } \\
\hline 1 & Irfan Ahmad & $\begin{array}{l}\text { Study design, Data collection, } \\
\text { analysis, drafting and revision. } \\
\text { Study design, Data collection, } \\
\text { analysis, drafting and revision. } \\
\text { Study design, Data collection, } \\
\text { analysis, drafting and revision. }\end{array}$ \\
\hline 3 & Zafar Majeed & Javed lqbal
\end{tabular}

